\title{
Serum surfactant protein D: Biomarker of chronic obstructive pulmonary disease
}

\author{
Chun-Rong Ju, Wei Liu and Rong-Chang Chen* \\ State Key Lab of the Respiratory Disease, Guangzhou Institute of Respiratory Disease, First Affiliated Hospital of \\ Guangzhou Medical College, Guangdong, China
}

\begin{abstract}
Background: Surfactant protein D (SP-D) is a lung-specific protein proposed to predict clinical outcomes in patients with chronic obstructive pulmonary disease (COPD). However, the changes in serum SP-D during acute exacerbation (AECOPD) episodes and the relationship of serum SP-D with the overall severity of the disease in stable COPD (SCOPD) remain unclear. Methods: Serum SP-D levels were analyzed in three groups, including AECOPD $(n=40)$, SCOPD $(n=71)$, and controls $(n=60)$. In AECOPD group, serum SP-D levels were determined at $1,5,14$, and 30 days post-exacerbation. In SCOPD group, BODE (body mass index, airflow obstruction, dyspnea, exercise capacity) index was evaluated for severity assessment.

Results: Serum SP-D levels were sequentially elevated from the controls to the SCOPD, and then to the AECOPD $(p<0.001)$. During an AECOPD episode, the raised serum SP-D levels subsided at day 5 ( $p>0.05)$, fell markedly at day $14(p<0.001)$, and continued to decline at day $30(p<0.001)$. Among patients with SCOPD, serum SP-D levels correlated positively with the BODE index $(p<0.01)$.

Conclusions: The longitudinal changes in serum SP-D levels during an AECOPD episode suggest that SP-D may be a potential systemic biomarker for COPD exacerbation. The correlation of serum SP-D levels with the BODE index suggests that circulating SP-Ds can reflect the overall severity of SCOPD.
\end{abstract}

Keywords: BODE index, COPD, exacerbation, surfactant protein D (SP-D), airflow limitation

\section{Introduction}

Chronic obstructive pulmonary disease (COPD) is a major medical problem, as well as a leading cause of morbidity and mortality among adults. The definition of COPD has previously been based on pulmonary pathophysiology, i.e., airflow limitation that is not fully reversible and usually progressive. The current definition recognizes COPD as a multicomponent disease associated with systemic inflammation [1], which contributes to some of the extra-pulmonary consequences of COPD [2-4]. Both pulmonary and systemic inflammation flare up during episodes of acute exacerbation of COPD (AECOPD) that occur as natural events in patients [5]. The severity of airway inflammation dur-

\footnotetext{
*Corresponding author: Rong-Chang Chen, State Key Lab of the Respiratory Disease, Guangzhou Institute of Respiratory Disease, First Affiliated Hospital of Guangzhou Medical College, Guangdong, China. Tel.: +86 20 83062870; Fax: +86 20 83062729; E-mail: chenrc@163.vip.com.
}

ing AECOPD is associated positively with systemic inflammation, with a variety of systemic markers elevated in the circulation [6,7]. Most of these circulating biomarkers, such as $\mathrm{C}$ reactive protein (CRP) and tumor necrosis alpha, are not lung-specific. Surfactant protein D (SP-D) is a large multimeric collagenous glycoprotein produced mainly by type II epithelial and Clara cells in the lungs [8], and is also detected in the serum. Serum SP-D has been identified as a potential systemic biomarker for some pulmonary diseases, such as respiratory syncytial virus bronchiolitis [10], idiopathic interstitial fibrosis [9], acute respiratory distress syndrome [11], and allergic bronchopulmonary aspergillosis [12]. Serum SP-D is a candidate biomarker for AECOPD because it increases in patients experiencing acute exacerbation [13]. However, the process by which the increased SP-D levels are modified upon the resolution of an AECOPD episode is unknown. Serum SP-D is also recognized as a biomarker for tracing the health outcomes of patients with stable COPD (SCOPD) [14]. However, the association of serum SP- 
D levels with BODE [body mass index (BMI), airflow obstruction, dyspnea and exercise capacity] index in SCOPD is unclear. The BODE index is a multidimensional COPD index proven to be better than forced expiratory volume in the 1 st second $\left(\mathrm{FEV}_{1}\right)$ in predicting the risk of death of patients. Thus, the present study aims to analyze the changes in serum SP-D levels from the onset of acute exacerbation to one month after the episode. The relationship of the serum SP-D levels to the BODE index in SCOPD is also ascertained.

\section{Materials and methodology}

\subsection{Subjects and study design}

The present research was approved by the Research Committee of Human Investigation of Guangzhou Medical College. Informed consent was obtained from each participant. The study subjects were divided into three groups, including 40 patients with AECOPD episodes, 71 patients with SCOPD, and 60 healthy controls. The diagnosis of COPD was in accordance to Gold guidelines [15], with an exclusion of significant diagnosed co-morbidity. AECOPD was defined as the worsening of respiratory symptoms, including increased sputum volume, purulent sputum, and/or breathlessness. Patients with AECOPD were recruited from the inpatient department of the Guangzhou Institute of Respiratory Disease, First Affiliated Hospital of Guangzhou Medical College. The routine management for AECOPD during admission was as follows: systemic corticosteroids (injection of methylprednisolone $0.75 \mathrm{mg} / \mathrm{kg}$ per day for the first 3 days to 5 days, and switching to oral methylpredinisone for the following 6 days to 9 days), antibiotics, oxygen therapy, and nebulized bronchodilators. Inhaled corticosteroids (ICS) and long-acting $\beta_{2}$ agonists were prescribed for maintenance therapy upon discharge. A serial assessment of serum levels of SP-D was conducted at the following time points: day 1 of admission (prior to treatment after hospitalization for AECOPD); day 5, day 14, and day 30. Patients with SCOPD were recruited from the outpatient department of the same hospital mentioned above. The inclusion criteria were as follows: spirometry-established diagnosis of COPD, former smokers, and in stable condition for at least three months. About $85 \%$ of the patients were receiving ICS (400 $\mu \mathrm{g}$ to $800 \mu \mathrm{g}$ of budesonide equivalent dose per day) and bronchodilators as maintenance therapy. None of the patients was on regular systemic corticos- teroids. The control group was recruited from the regular check-up department in the same hospital. The criteria for inclusion in control group were as follows: normal spirometry, non-smoker or has abstained from smoking for more than 10 years, and no history of medical illness at the time of the study.

\subsection{Measurements of SP-D and CRP}

Peripheral venous blood was collected from each subject and centrifuged at $5000 \mathrm{rpm}$ for $10 \mathrm{~min}$ at $4^{\circ} \mathrm{C}$. The serum samples were immediately stored at $-80^{\circ} \mathrm{C}$ until analyzed. Serum SP-D levels were determined using commercially available enzyme-linked immunosorbent assay (ELISA) kits from BioVendor (USCN Life Science \& Technology Co.). CRP was detected by ELISA kits from CHEMICON Inter. Co.

\subsection{Pulmonary function test}

Spirometry was performed on each subject. Reversibility assessments were conducted in COPD patients by making them inhale a short-acting $\beta 2$ agonist equivalent to $200 \mu \mathrm{g}$ salbutamol. For the hospitalized patients with acute exacerbations, spirometry was performed 7 days to 10 days after the onset of exacerbation when the patients were stable enough to perform the spirometric maneuver. For patients with SCOPD and for the healthy controls, spirometry was performed on the same day of blood sampling.

\subsection{Calculation of BODE index}

The BODE index was calculated for all patients with SCOPD using the score proposed by Celli et al. [16]. Dyspnea was assessed according to the modified Medical Research Council scale [17]. Exercise capacity was evaluated using the six-minute-walk distance test based on the guidelines of the American Thoracic Society [18]. BODE index was calculated using variables obtained within 4 weeks of enrolment, and the total possible values ranged from 0 to 10 .

\subsection{Statistical analyses}

Statistical analysis was performed using SPSS 12.0 package for Windows (SPSS Inc, Chicago, IL, USA) and Graphpad Prism v. 5 (Graphpad Software Inc., San Diego, CA, USA). Normally distributed data were expressed as mean \pm standard deviation (SD). Non-normally distributed data were expressed as me- 
Table 1

The basic information about the study participants

\begin{tabular}{|c|c|c|c|}
\hline & Healthy elderly & SCOPD & AECOPD \\
\hline Number (M/F) & $60(21 / 39)$ & $71(54 / 17)$ & $40(38 / 2)$ \\
\hline Ages (years) & $63.98 \pm 5.77$ & $65.17 \pm 6.80$ & $66.05 \pm 5.67$ \\
\hline BMI $(\mathrm{kg} / \mathrm{m} 2)$ & $22.64 \pm 2.24$ & $19.15 \pm 3.19^{* *}$ & $18.07 \pm 3.39^{* * \dagger}$ \\
\hline $\mathrm{FEV}_{1} \%$ pred (\%) & $97.1 \pm 8.90$ & $37.76 \pm 14.93^{* *}$ & $33.78 \pm 7.39^{* * \dagger}$ \\
\hline $\mathrm{FEV}_{1} / \mathrm{FVC}(\%)$ & $88.95 \pm 9.52$ & $43.97 \pm 12.44^{* *}$ & $40.71 \pm 6.61^{* * \dagger}$ \\
\hline SP-D (ng/ml) & $103.05 \pm 24.97$ & $153.54 \pm 45.21^{* *}$ & $235.22 \pm 48.27^{* * \dagger \dagger}$ \\
\hline $\mathrm{CRP}(\mathrm{mg} / \mathrm{L})$ & $3.12(0.76-8.94)$ & $3.21(0.54-6.93)$ & $15.66(5.49-39.79)^{* * \dagger \dagger}$ \\
\hline \multicolumn{4}{|c|}{$\begin{array}{l}\text { AECOPD }=\text { acute exacerbation of } \mathrm{COPD} ; \mathrm{BMI}=\text { body mass index; } \mathrm{COPD}=\text { chronic } \\
\text { obstructive pulmonary disease; } \mathrm{FEV}_{1}=\text { forced expiratory volume at } 1 \mathrm{~s} ; \% \text { pred }=\text { percent } \\
\text { of predicted value; } \mathrm{FVC}=\text { forced vital capacity; } \mathrm{SP}-\mathrm{D}=\text { surfactant protein } \mathrm{D} ; \\
{ }^{*} p<0.05,{ }^{* *} p<0.01, \text { vs. Controls; }{ }^{\dagger} p<0.05,{ }^{\dagger \dagger} p<0.01, \text { vs. SCOPD; } \\
\text { Values are mean } \pm \mathrm{SD} \text { or median (range). }\end{array}$} \\
\hline
\end{tabular}

dian (range). The level of statistical significance was set at $p<0.05$. The differences among the three groups (controls, SCOPD, and AECOPD) were tested by ANOVA with the least significant difference test for post-hoc pairwise comparison procedures. Chi-square testing was used to compare the proportion of categorical variables among groups. In the AECOPD group, the changes in the serum SP-D levels between day 1 and the different time points were calculated and expressed as a percentage of the value of the sample at day 1 . In the SCOPD group, multiple linear regression modeling was performed to determine the independent relationship of serum SP-D levels with the BODE index and airflow limitation ( $\mathrm{FEV}_{1} \%$ pred). Adjustments were made for confounding factors, including age, sex, BMI, and smoking status at the time of blood sampling.

\section{Results}

\subsection{Characteristics of the subjects}

Table 1 summarizes the clinical characteristics of all COPD patients and healthy controls. There was no significant difference among the ages of the three groups. The lung function parameters and BMI were lower and tobacco exposure was greater in COPD patients compared with controls. Two cases in the AECOPD group were excluded from the final analysis because the patients had persistent symptoms that did not improve after treatment until the 30th day of the exacerbation.

\subsection{Serum $S P-D$ and $C R P$ levels}

The serum SP-D levels of the three groups are shown in Table 1. Figure 1 shows that serum SP-D was highest in the AECOPD group, followed by the SCOPD

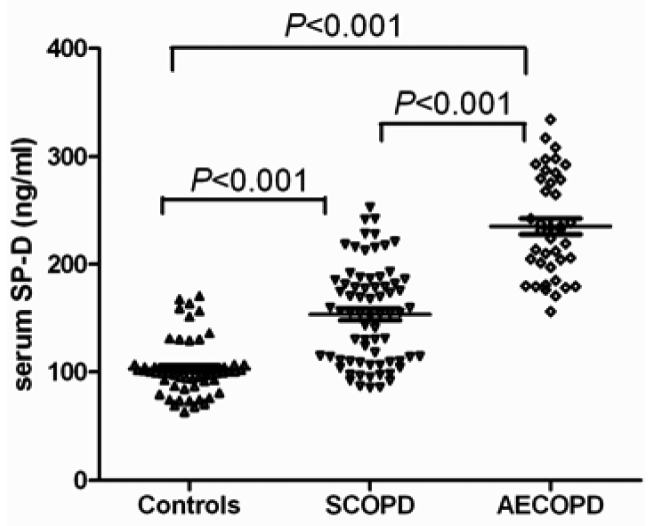

Fig. 1. Analysis (mean $\pm \mathrm{SD}$ ) of the serum SP-D levels showed higher levels in SCOPD and much higher levels in AECOPD compared with those of the controls.

group, and lastly, by the control group ( $p<0.001)$. The time trends of serum SP-D and CRP levels in the AECOPD group are shown in Figs $2 \mathrm{~A}$ and $2 \mathrm{~B}$, respectively. The SP-D level was highest in day 1 and subsided at day $5[(226.17 \pm 49.77) \mathrm{ng} / \mathrm{mL}](p>0.05)$, decreased markedly at day $14[(190.02 \pm 36.9) \mathrm{ng} / \mathrm{mL}](p<$ $0.001)$, and continued to decline at day $30[(163.87 \pm$ $33.27) \mathrm{ng} / \mathrm{mL}](p<0.001)$. The serum CRP level had a similar trend.

\subsection{BODE index}

The BODE index and its components, as well as the serum SP-D levels in patients with SCOPD, are shown in Table 2, with the stratification of the COPD severity based on Gold guidelines.

\subsection{Correlations}

Figures $3 \mathrm{~A}$ and $3 \mathrm{~B}$ show the correlation of serum SP-D levels with $\mathrm{FEV}_{1} \%$ pred and the BODE index in 
Table 2

SP-D levels and BODE index in patients with stable disease

\begin{tabular}{lccc}
\hline & Stage II & Stage III & Stage IV \\
\hline Number (\%) & $13(18 \%)$ & $28(39 \%)$ & $30(42 \%)$ \\
BMI $\left(\mathrm{kg} / \mathrm{m}^{2}\right)$ & $21.15 \pm 2.81$ & $18.61 \pm 2.70$ & $18.79 \pm 3.56$ \\
FEV $\%$ pred (\%) & $62.62 \pm 6.52$ & $39.62 \pm 6.65$ & $25.29 \pm 5.47$ \\
MMRC dyspnea scale (score) & $0.85 \pm 0.80$ & $2.18 \pm 0.67$ & $3.0 \pm 0.1$ \\
6MWT distance (m) & $564.15 \pm 108.82$ & $345.86 \pm 87.73$ & $235.07 \pm 70.94$ \\
BODE index (score) & $2.46 \pm 1.51$ & $6.21 \pm 1.83$ & $8.70 \pm 0.92$ \\
SPD (ng/ml) & $120.82 \pm 34.11$ & $135.54 \pm 36.51$ & $184.53 \pm 37.74$ \\
\hline
\end{tabular}

$\mathrm{BMI}=$ Body mass index; $\mathrm{FEV}_{1}=$ forced expiratory volume at $1 \mathrm{~s} ; \%$ pred $=$ percent of predicted value; $\mathrm{FVC}=$ forced vital capacity; $\mathrm{MMRC}=$ modified Medical Research Council; 6MWT $=6$-min walk test; SP-D = surfactant protein D;

Values are mean \pm SD or percentage.
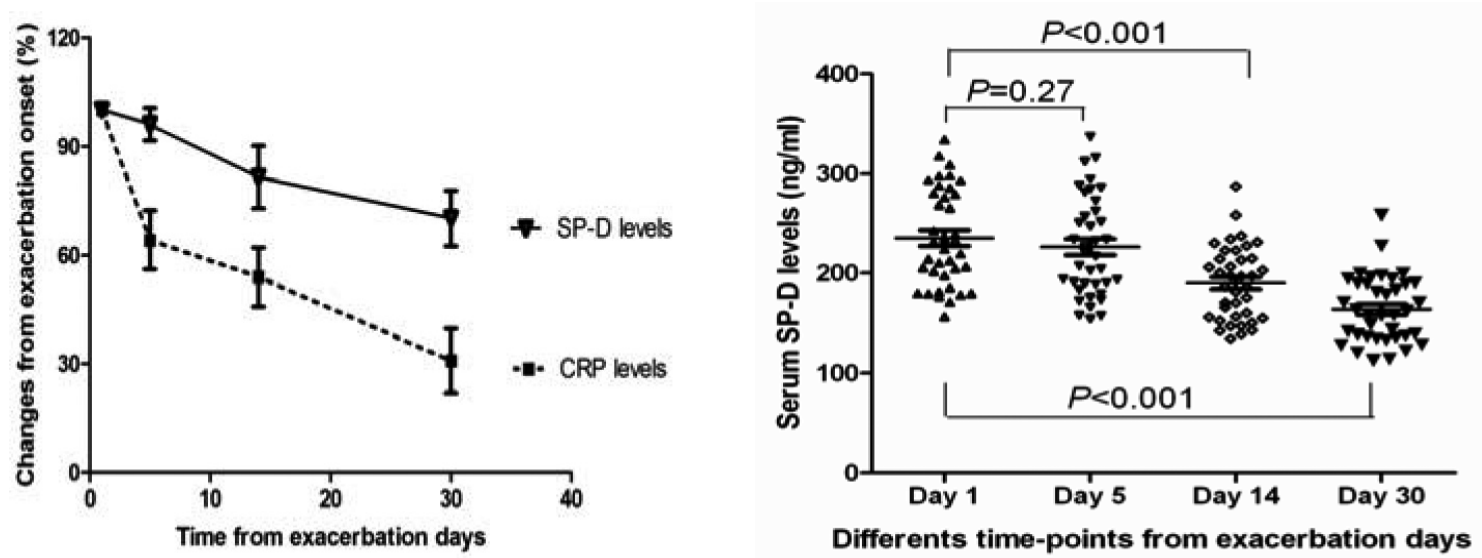

Fig. 2. (A) Time trend of serum SP-D and CRP levels in 38 patients whose symptoms had recovered from the AECOPD episodes. Data are expressed as percentages of the values of the exacerbation onset sample. (B) Serum SP-D levels (mean \pm SD) in these patients at different time points after exacerbation days.

SCOPD group. Multiple regression analysis revealed that the serum SP-D levels were significantly correlated inversely with $\mathrm{FEV}_{1} \%$ pred [beta coefficient $=$ -0.563 , and $95 \%$ confidence interval $(\mathrm{CI})=-2.324$ to -1.113 ], and positively with BODE index (beta coefficient $=0.558$, and $95 \% \mathrm{CI}=6.062$ to 12.795$)$ (both $p<0.01)$.

\section{Discussion}

The present work was both a longitudinal and a cross-sectional study. Longitudinal in the sense that the changes in the serum SP-D levels from days 1 to 30 after an exacerbation of COPD were investigated; crosssectional in the sense that the differences among the serum SP-D levels of AECOPD, SCOPD, and healthy controls were analyzed. The following are our principal findings: (1) Serum SP-D levels were significantly increased in patients experiencing an AECOPD episode. The increased SP-D levels subsided at day 5 post-exacerbation and thereafter fell gradually within 30 days. (2) In patients with SCOPD, the serum SP-D levels correlated positively with the BODE index and inversely with $\mathrm{FEV}_{1} \%$ pred.

The serum SP-D levels were also significantly elevated in both AECOPD and SCOPD groups compared with the healthy controls, with the highest levels in the AECOPD group. This finding was consistent with that reported by Shakooria et al. [13], wherein the serum SP-D levels were significantly higher in AECOPD than in SCOPD or controls. As for the dynamic changes in serum SP-D during and after acute COPD exacerbation, no previous report was found in Medline. Although Shakooria [13] reported the remarkable elevation of serum SP-D levels during AECOPD episodes, the dynamic changes in serum SP-D levels after exacerbation were not reported. The potential mechanisms related to the gradual fall of serum SP-D after exacerbation are unclear. One of the potential mechanisms 

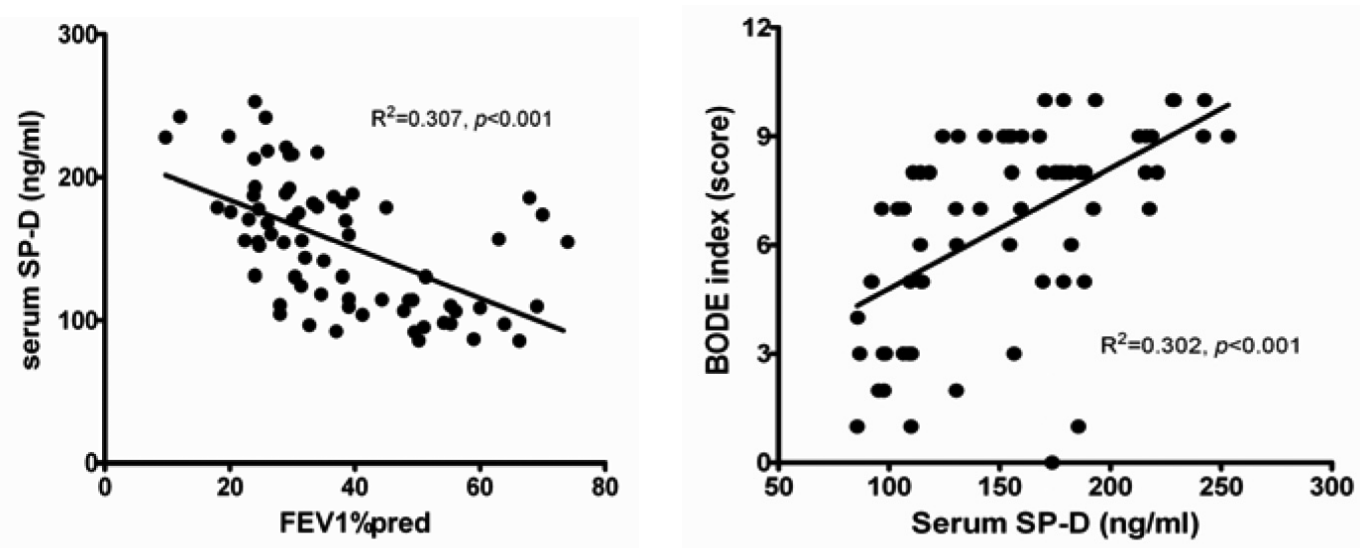

Fig. 3. Relationship of serum SP-D levels with (A) BODE index and (B) FEV1\%pred among patients with SCOPD.

might be attributed to the alleviation of the inflammation related to the corticosteroid and antibiotic treatments for our study patients. According to the current, most widely accepted hypothesis, SP-D translocates from the pulmonary site into the systemic circulation, a process that could be regulated by changes in alveolar-capillary permeability [19-21]. Serum SP-D is elevated in the circulation in response to lung pathology [22]. This hypothesis is supported by a recent finding that treatment with systemic steroids or ICS leads to decreased serum SP-D concentrations in COPD patients $[23,24]$. Therefore, the decreased serum SP-D levels were likely related to the improved permeability resulting from inflammation suppression by steroid treatment in our study patients with AECOPD. These findings were in line with the hypothesis, and indicated that decreased serum SP-D levels may reflect the retrogression of pulmonary inflammation. With regard to the association between serum SP-D and inflammation, Sin et al. [24] suggested that serum SP-D is a biomarker for anti-inflammatory therapy because treatment with ICS results in decreased serum SP-D levels and exhibits systemic anti-inflammatory effects in individuals with COPD. This suggestion further explains our results of lower serum SP-D levels at day 30 than day 14 because the patients continued to receive ICS during the recovery phase from the AECOPD episode.

We also observed that serum CRP levels were decreased markedly at day 5 , and continued to decline during the following days post-exacerbation in patients with AECOPD. The data was in agreement with that of Perera et al. [25]. Currently, CRP is the most commonly used acute-phase reactant for the routine diagnosis of infectious diseases [26], and may assist in the identification of high-risk patients with AECOPD [27].
In the present study, CRP fell more rapidly than SP$\mathrm{D}$ in circulation when the exacerbation began to subside. An exacerbation is associated with lung injury in COPD [28]; therefore, the delay of the decline in the serum SP-D levels may be attributed to the time taken to repair the leakage of the pulmonary alveolar-capillary barrier when the exacerbation is resolved. CRP is an acute-phase reactant produced by the liver and rapidly secreted into the circulation. Hurst et al. [29] demonstrated that CRP is a biomarker for differentiating AECOPD from day-to-day symptom variations after assessing the value of 36 biomarkers. However, the serum SP-D levels have not been determined. CRP is not lung-specific because it is increased in most conditions associated with infection, tissue damage, or inflammation [30,31]. By contrast, SP-D produced mainly by type II epithelial and Clara cells in the lungs is reported to be increased in several lung diseases [32-34] or other diseases involved in lung injury $[35,36]$. The sensitivity and specificity of serum SP-D in the diagnosis of AECOPD have also been demonstrated [13]. These previous findings and our results suggest that serum SP-D may be used as an effective systemic biomarker for AECOPD.

In patients with SCOPD, the serum SP-D levels were also significantly elevated compared with those of the controls. This finding was in line with a large study of patients with and without COPD, where the ECLIPSE investigators [37] found higher serum SP-D levels in COPD patients than in healthy smoking controls. We found an inverse correlation between serum SP-D levels and $\mathrm{FEV}_{1} \%$ pred in patients with SCOPD. However, the ECLIPSE investigators failed to find a significant relationship between $\mathrm{FEV}_{1}$ and SP-D. The likely explanation may be the difference between the patient 
populations. Our study patients were former smokers who had abstained from smoking for more than 3 years, whereas $40 \%$ of the patients in the ECLIPSE study were current smokers. According to their results, the serum SP-D levels are affected by smoking, which may interfere with the homogeneity of serum SP-D concentrations. Another likely explanation for the difference is that most of our study patients had more severe COPD than those in the ECLIPSE study. Thus, their data are not generalized to patients with severe or very severe COPD. Nevertheless, our findings were in accord with those of Sin et al. [38], who showed an inverse correlation between circulating SP-D and $\mathrm{FEV}_{1}$ in COPD, and with those of Winkler et al. [23], who found an inverse correlation of serum SP-D levels with $\mathrm{FEV}_{1} / \mathrm{FVC}$ in COPD. Serum SP-D is considered a useful biomarker for tracking the health outcomes of COPD patients [38]. Consistently, we observed a positive correlation between serum SP-D levels and the BODE index in patients with SCOPD. The BODE index is a multidimensional index of disease severity in COPD that incorporates four factors known to be independent predictors of survival in this disease. The BODE index has been proven to be a good predictor of survival in a large cohort of patients with COPD and corresponds to important differences in the health status of COPD patients [39]. The BODE index is likely to predict outcomes more accurately than $\mathrm{FEV}_{1}$ in COPD [40]. Thus, serum SP-D may be used as a promising biomarker for the evaluation and follow-up of COPD patients, including the evaluation of treatment responses.

\subsection{Limitations}

The current study has several limitations. First, we are not certain whether the duration of our study was long enough to comprehensively track the impact of AECOPD on serum SP-D. We do not know if the exacerbations had relatively long-term effects on the expression of serum SP-D in COPD patients. Second, for patients with AECOPD, there was no baseline serum SP-D level before the acute exacerbation. We cannot determine the dynamic rise in serum SP-D during the onset of acute exacerbation. We also cannot rule out the possibility that the patients with AECOPD had higher baseline levels of serum SP-D. Third, bronchoalveolar lavage fluid (BALF) was not obtained in our study. We are not aware of the changes in SP-D in BALF and how the SP-D in BALF is related to serum SP-D. Fourth, the patients with SCOPD were on a variety of ICS, and the ones with AECOPD were on systemic steroids, which could modify the serum expression of SP-D, thereby interfering with the results. Finally, most of the patients in our study had severe or very severe COPD, such that these data cannot be generalized to patients with mild or moderate disease. Further studies are needed to address these issues.

\section{Conclusion}

The present study showed that the serum levels of SP$\mathrm{D}$ were markedly elevated early in patients with acute COPD exacerbation, but eventually declined with time. The serum SP-D levels were correlated with the BODE index and $\mathrm{FEV}_{1} \%$ pred in SCOPD patients. SP-D may be a potential systemic biomarker for COPD exacerbation and can reflect the overall severity of SCOPD.

\section{Acknowledgements}

We would like to thank all the participants of the present study. We thank Dr. Shi-yue Li (Director of Respiratory Medicine, Guangzhou Institute of Respiratory Disease) for his support and cooperation in making this work a success. We thank all the nurses of Respiratory Medicine for their help with the blood sampling. Our project was supported by the Special Funds of the National Natural Science Foundation of China (Grant No. 838239) and the Special Funds for Young Investigator of Guangzhou Medical College (No. 2010A06).

\section{Conflicts of interest declaration}

None of the authors have any potential conflict of interest to declare in this article.

\section{References}

[1] Gan WQ, Man SF, Senthilselvan A, et al. Association between chronic obstructive pulmonary disease and systemic inflammation: a systematic review and a meta-analysis, Thorax 59 (2004), 574-580.

[2] Barnes PJ, Celli BR. Systemic manifestations and comorbidities of COPD, Eur Respir J 33 (2009), 1165-1185.

[3] Maclay JD, McAllister DA, Mills NL, et al. Vascular dysfunction in chronic obstructive pulmonary disease, Am J Respir Crit Care Med 180 (2009), 513-520.

[4] Agusti AG, Noguera A, Sauleda J, et al. Systemic effects of chronic obstructive pulmonary disease, Eur Respir J 21 (2003), 347-360. 
[5] Emiel F.M. Wouters1, Karin H. et al. Systemic inflammation in chronic obstructive pulmonary disease: The role of exacerbations, Proc Am Thorac Soc 4 (2007), 626-634.

[6] Kersul AL, Iglesias A, Ríos Á, Molecular mechanisms of inflammation during exacerbations of chronic obstructive pulmonary disease, Arch Bronconeumol 47 (2011), 176-183.

[7] Hurst JR, Perera WR, Wilkinson TM, et al. Exacerbation of chronic obstructive pulmonary disease: pan-airway and systemic inflammatory indices, Proc Am Thorac Soc 3 (2006), 481-482.

[8] Palaniyar N, Zhang L, Kuzmenko A, et al. The role of pulmonary collectin $\mathrm{N}$-terminal domains in surfactant structure, function, and homeostasis in vivo, J Biol Chem 277 (2002), 26971-26979.

[9] Kawasaki Y, Endo K, Suyama K, Sato M, Ito M, Hashimoto K, Hosoya M. Serum SP-D levels as a biomarker of lung injury in respiratory syncytial virus bronchiolitis, Pediatr Pulmonol 46 (2011), 18-22.

[10] Ohnishi H, Yokoyama A, Kondo K, et al. Comparative study of KL-6, surfactant protein-A, surfactant protein-D, and monocyte chemoattractant protein-1 as serum markers for interstitial lung diseases, Am J Respir Crit Care Med 165 (2002), 378-381.

[11] Eisner MD, Parsons P, Matthay MA, et al. Plasma surfactant protein levels and clinical outcomes in patients with acute lung injury. Thorax 58 (2003), 983-988.

[12] Krane M, Griese M. Surfactant protein D in serum from patients with allergic bronchopulmonary aspergillosis. Eur Respir J 22 (2003), 592-595.

[13] Shakooria TA, Sin DD, Ghafoor F, et al. Serum surfactant protein D during acute exacerbations of chronic obstructive pulmonary disease, Dis Markers 27 (2009), 287-294.

[14] Sin DD, Pahlvan PS, Man SFP. Review: Surfactant protein D: A lung specific biomarker in COPD? Ther Adv Resp Dis 2 (2008), 65-74.

[15] Global Initiative for Chronic Obstructive Lung Disease. Available at: www.goldcopd.com. Accessed March 11, (2008).

[16] Celli BR, Cote CG, Marı'n JM, et al. The body-mass index, airflow obstruction, dyspnea, and exercise capacity index in chronic obstructive pulmonary disease, $N$ Engl J Med 350 (2004), 1005-1012.

[17] Mahler D, Wells C. Evaluation of clinical methods for rating dyspnea, Chest 93 (1988), 580-586.

[18] ATS Committee on Proficiency Standards for Clinical Pulmonary Function Laboratories: ATS statement: guidelines for the six minute walk test, Am J Respir Crit Care Med 166 (2002), 111-117.

[19] Doyle IR, Nicholas TE, Bersten AD. Surfactant proteins A and $\mathrm{B}$ are elevated in plasma of patients with acute respiratory failure, Am J Respir Crit Care Med 12004 (1997), 1217-1229.

[20] Robin M, Dong P, Hermans C, et al. Serum levels of CC16, SP$\mathrm{A}$ and SP-B reflect tobacco-smoke exposure in asymptomatic subjects, Eur Respir J 20 (2002), 1152-1161.

[21] Hermans C, Bernard A. Lung epithelium-specific proteins: characteristics and potential applications as markers, Am J Respir Crit Care Med 159 (1999), 646-678.

[22] Hartl D, Griese M. Surfactant protein D in human lung diseases, Eur J Clin Invest 36 (2006), 423-435.

[23] Winkler C, Atochina-Vasserman EN, Holz O, et al. Comprehensive characterisation of pulmonary and serum surfactant protein D in COPD, Respir Res 12 (2011), 29
[24] Sin DD, Man S-FP, Marciniuk DD, et al. The effects of fluticasone with or without salmeterol on systemic biomarkers of inflammation in COPD, Am J Respir Crit Care Med 177 (2008), 1207-1214.

[25] Perera WR, Hurst JR, Wilkinson TM, et al. Inflammatory changes, recovery and recurrence at COPD exacerbation, Eur Respir J 29 (2007), 527-534.

26] Müller B, Tamm M. Biomarkers in acute exacerbation of chronic obstructive pulmonary disease: among the blind, the one-eyed is king, Am J Respir Crit Care Med 174 (2006), 848-849.

[27] Ruiz-González A, Lacasta D, Ibarz M, et al. C-reactive protein and other predictors of poor outcome in patients hospitalized with exacerbations of chronic obstructive pulmonary disease, Respirology 13 (2008), 1028-1033.

[28] Papi A, Bellettato CM, Braccioni F, et al. Infections and airway inflammation in chronic obstructive pulmonary disease severe exacerbations, Am J Respir Crit Care Med 173 (2006), 11141121.

[29] Hurst JR, Donaldson GC, Perera WR, et al. Use of plasma biomarkers at exacerbation of chronic obstructive pulmonary disease, Am J Respir Crit Care Med 174 (2006), 867-874.

[30] Pepys MB, Hirschfield GM. C-reactive protein: a critical update. J Clin Invest 111 (2003), 1805-1812.

[31] Mold C, Rodic-Polic B, Du Clos TW. Protection from Streptococcus pneumoniae infection by $\mathrm{C}$-reactive protein and natural antibody requires complement but not Fc receptors, J Immunol 168 (2002), 6375-6381.

[32] Hasegawa M, Fujimoto M, Hamaguchi Y, et al. Use of serum clara cell $16-\mathrm{kDa}(\mathrm{CC} 16)$ levels as a potential indicator of active pulmonary fibrosis in systemic sclerosis, J Rheumatol 38 (2011), 877-884.

[33] Kawasaki Y, Endo K, Suyama K, et al. Serum SP-D levels as a biomarker of lung injury in respiratory syncytial virus bronchiolitis, Pediatr Pulmonol 46 (2011), 18-22.

[34] Singh D, Edwards L, Tal-Singer R, et al. The radiological patterns of interstitial change at an early phase: over a 4-year follow-up, Respir Res 11 (2010), 77.

[35] Bonella F, Volpe A, Caramaschi P, et al. Surfactant protein D and KL-6 serum levels in systemic sclerosis: correlation with lung and systemic involvement, Sarcoidosis Vasc Diffuse Lung Dis 28 (2011), 27-33.

[36] Osaka A, Yanagihara K, Yamada Y, et al. Elevation of serum KL-6 glycoprotein or surfactant protein-D in adult T-cell leukemia with distinct pulmonary complications, Tohoku $J$ Exp Med 218 (2009), 99-105.

[37] Lomas DA, Silverman EK, Edwards LD, et al. Serum surfactant protein $\mathrm{D}$ is steroid sensitive and associated with exacerbations of COPD, Eur Respir J 34 (2009), 95-102.

[38] Sin DD, Leung R, Gan WQ, et al. Circulating surfactant protein $\mathrm{D}$ as a potential lung-specific biomarker of health outcomes in COPD: a pilot study, BMC Pulm Med 7 (2007), 13.

[39] Ong KC, Lu SJ, Soh CS. Does the multidimensional grading system (BODE) correspond to differences in health status of patients with COPD? Int J Chron Obstruct Pulmon Dis 1 (2006), 91-96.

40] Ong KH, Earnest A, Lu SJ. A multidimensional grading system (BODE index) as a predictor of hospitalization for COPD, Chest 128 (2005), 3310-3316. 


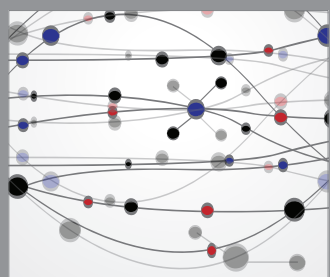

The Scientific World Journal
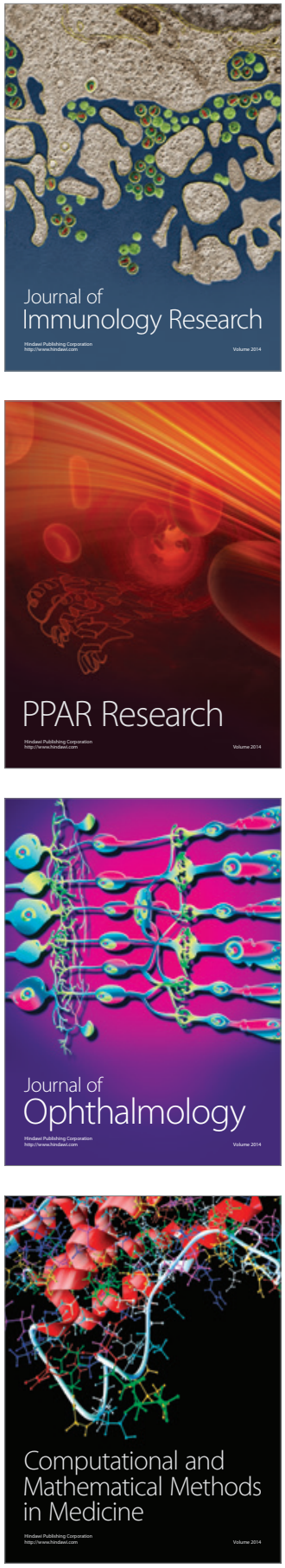

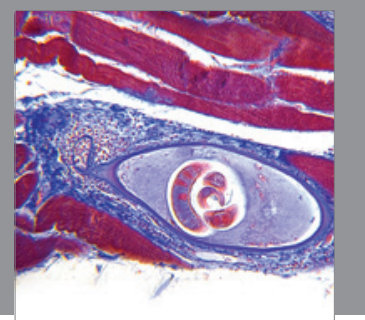

Gastroenterology

Research and Practice
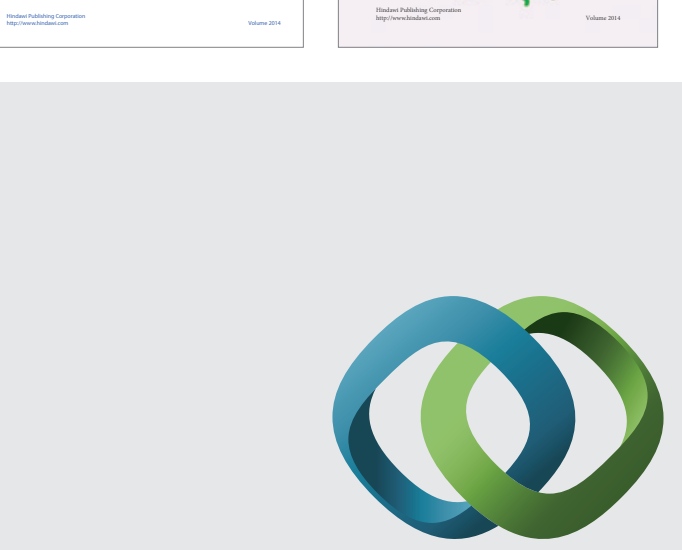

\section{Hindawi}

Submit your manuscripts at

http://www.hindawi.com
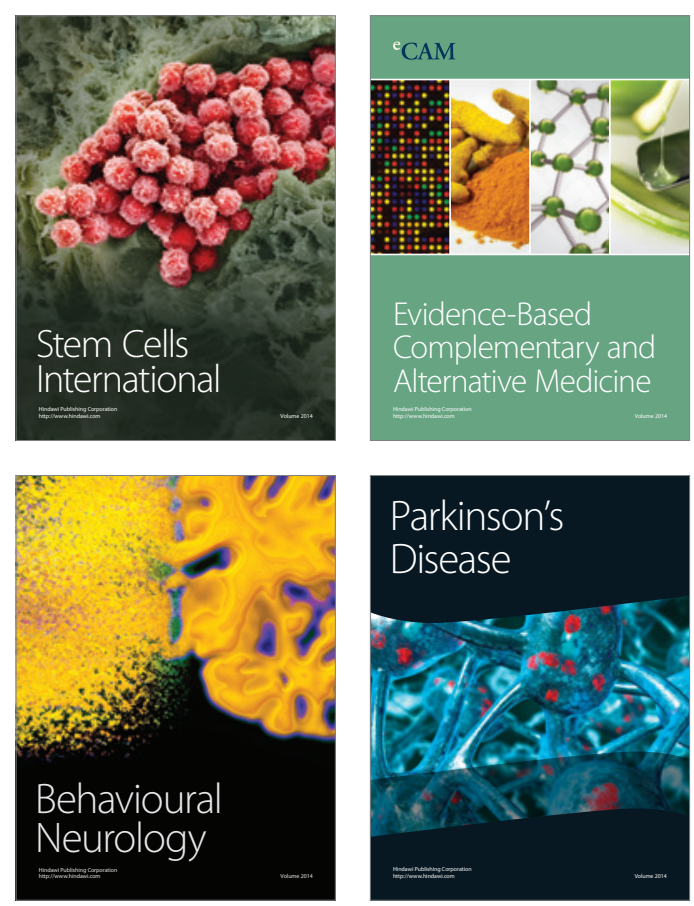

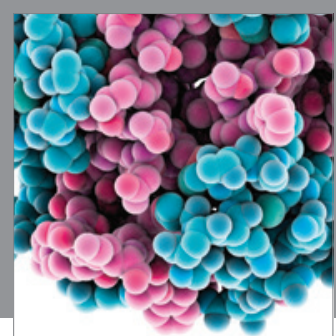

Journal of
Diabetes Research

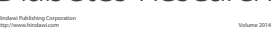

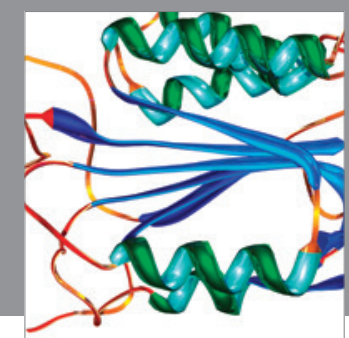

Disease Markers
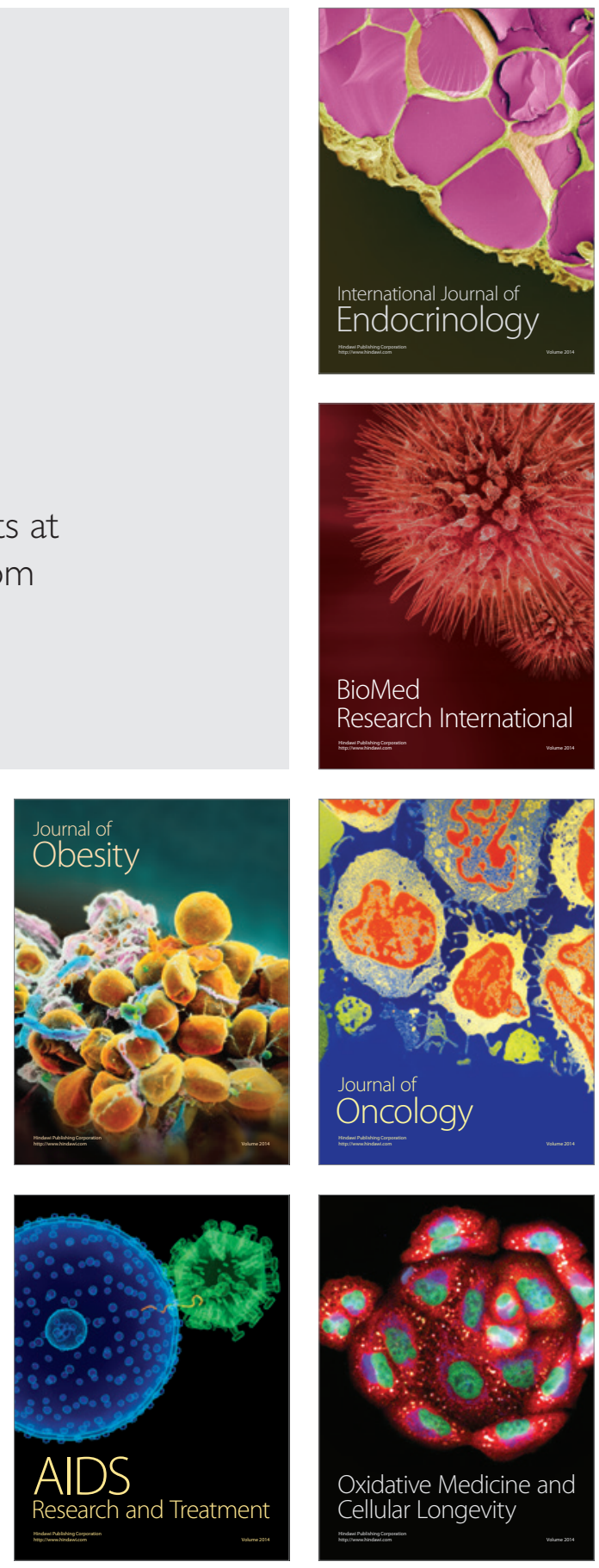